\title{
Ameliorative Effect of Vitamin C on Alterations in Thyroid Hormones Concentrations Induced by Subchronic Coadministration of Chlorpyrifos and Lead in Wistar Rats
}

\author{
Suleiman F. Ambali, Chinedu Orieji, Woziri O. Abubakar, Muftau Shittu, \\ and Mohammed U. Kawu \\ Department of Veterinary Physiology and Pharmacology, Ahmadu Bello University, Zaria 800007, Nigeria \\ Correspondence should be addressed to Suleiman F. Ambali, fambali2001@yahoo.com
}

Received 13 January 2011; Revised 24 March 2011; Accepted 30 March 2011

Academic Editor: Duncan Topliss

Copyright (C) 2011 Suleiman F. Ambali et al. This is an open access article distributed under the Creative Commons Attribution License, which permits unrestricted use, distribution, and reproduction in any medium, provided the original work is properly cited.

\begin{abstract}
The present study evaluated the ameliorative effect of vitamin $\mathrm{C}$ on alteration in thyroid hormones induced by low-dose subchronic coadministration of chlorpyrifos $(\mathrm{CPF})$ and lead $(\mathrm{Pb})$. Forty Wistar rats were divided into 4 groups of 10 animals each. Groups I and II were administered soya oil $(2 \mathrm{~mL} / \mathrm{kg})$ and vitamin C $(100 \mathrm{mg} / \mathrm{kg})$, respectively. Group III was coadministered CPF $\left(4.25 \mathrm{mg} / \mathrm{kg} \sim 1 / 20\right.$ th $\left.\mathrm{LD}_{50}\right)$ and $\mathrm{Pb}\left(250 \mathrm{mg} / \mathrm{kg} \sim 1 / 20\right.$ th $\left.\mathrm{LD}_{50}\right)$, respectively. Group IV was pretreated with vitamin $\mathrm{C}$ $(100 \mathrm{mg} / \mathrm{kg})$ and then coadministered with CPF $(4.25 \mathrm{mg} / \mathrm{kg})$ and $\mathrm{Pb}(250 \mathrm{mg} / \mathrm{kg}), 30 \mathrm{~min}$ later. The regimens were administered by gavage for a period of 9 weeks. The marginal decrease in serum triiodothyronine and thyroxine and the significant increase in the concentrations of thyroid stimulating hormone and malonaldehyde in the group coadministered with $\mathrm{CPF}$ and $\mathrm{Pb}$ were ameliorated by vitamin $\mathrm{C}$ partly due to its antioxidant properties.
\end{abstract}

\section{Introduction}

Man and animals are exposed to a "soup" of chemical contaminants in the environment, which directly or indirectly affect their health and well-being. Pesticides and heavy metals are the most common environmental contaminants because of their respective widespread use in agriculture and industries. Hitherto, most studies on these chemical contaminants have centered on the examination of one single agent and therefore, current understanding of the toxicity of many environmental toxicants/pollutants is based primarily on toxicity studies performed on laboratory animals exposed to a single toxic agent $[1,2]$. However, the environment is heavily contaminated with many chemicals, which interact with each other in such a way that modify their toxic response in humans and animals.

Organophosphate (OP) compounds are the most widely used insecticides accounting for $50 \%$ of global insecticidal use [3] while $\mathrm{Pb}$ is the most widespread heavy metal contaminants with wide applications [4]. Occupational and environmental $\mathrm{Pb}$ exposure continues to be among the most significant public health problems [4-7]. Due to their persistent nature in the environment and their toxicodynamics, $\mathrm{CPF}$ and $\mathrm{Pb}$ have resulted in deleterious effects in man and animals [8].

The toxicity of $\mathrm{Pb}$ remains a matter of public health concern [9] due to its pervasiveness in the environment and the awareness about its toxic effects [10] at exposure levels lower than what was previously considered harmful [11]. Reproductive consequences of $\mathrm{Pb}$ exposure are widespread [12], affecting almost all aspects of reproduction [13]. $\mathrm{Pb}$ induces decreased sperm count and motility and increased morphological abnormalities in animals $[14,15]$. CPF is one of the most common insecticidal environmental contaminants $[16,17]$. Despite restrictions placed on some of its domestic uses by United States Environmental Protection Agency (USEPA) in 2000, CPF is still widely used as residues have been detected in citrus fruits in some parts of the world [18]. Adverse reproductive outcomes have been observed following CPF poisoning [16, 17, 19-21]. The 
adverse reproductive health outcomes even as a result of environmental exposure to CPF have been partly linked to hypothyroidism [17]. Furthermore, other studies have found hypothyroidism in both $\mathrm{CPF}[17,22-24]$ and $\mathrm{Pb}$ [25-28] poisonings. Since adequate thyroidal function is essential for effective and optimal reproductive performance, therefore, measures aimed at mitigating the thyroid dysfunction instigated by exposure to low-dose environmental contaminants are pertinent.

Although the mechanisms of toxicity of the two agents differ, oxidative stress is a common feature in CPF [2933] and $\mathrm{Pb}$ [34-36] poisoning. However, ascorbic acid has shown tremendous promise in mitigating toxicity evoked by $\mathrm{CPF}[31,33,37,38]$ and $\mathrm{Pb}[28,39]$. Therefore, the present paper was aimed at evaluating the effect of low dose subchronic exposure to $\mathrm{CPF}$ and $\mathrm{Pb}$ on thyroid functions, the role of thyroidal lipoperoxidation, and ameliorative effect of vitamin $\mathrm{C}$ in Wistar rats.

\section{Material and Methods}

2.1. Experimental Animals. Forty 6-week-old adult male Wistar rats were obtained from the Animal House of the Department of Veterinary Physiology and Pharmacology, Ahmadu Bello University, Zaria, Nigeria. The rats were fed on standard rat pellets, and water was provided ad libitum. The experiment was performed in compliance with the National Institutes of Health Guide for Care and Use of Laboratory Animals [40].

2.2. Chemicals. Commercial grade CPF (Termicot 20\% EC, Sabero Organics, Gujarat, India) was reconstituted in soya oil to $10 \%$ solution, which was subsequently used for the experiment. Analytical grade lead acetate (Kiran Light Laboratories, Mumbai, India) used for the study was reconstituted into a $20 \%$ solution using distilled water. Commercial grade vitamin C tablets (100 mg/tablet; Emzor Pharmaceutical Ltd, Nigeria, BN : $618 \mathrm{~N}$ ) were dissolved in distilled water to $10 \%$ solution just before daily administration.

2.3. Animal Treatments. Forty adult male Wistar rats were divided into 4 groups of 10 animals per group. The rats in group I (C/oil) were administered corn oil $(2 \mathrm{~mL} / \mathrm{kg})$, while those in group II (VC) were administered vitamin C $(100 \mathrm{mg} / \mathrm{kg})$. Rats in group III $(\mathrm{CPF})$ were coadministered CPF $4.25 \mathrm{mg} / \mathrm{kg}, \sim 1 / 20$ th $\mathrm{LD}_{50}$ [24] and lead acetate $225 \mathrm{mg} / \mathrm{kg}, \sim 1 / 20$ th $\mathrm{LD}_{50}$ [28], respectively. Rats in group $\mathrm{IV}(\mathrm{VC}+\mathrm{CPF}+\mathrm{Pb})$ were pretreated with vitamin $\mathrm{C}$, and then coadministered with CPF $(4.25 \mathrm{mg} / \mathrm{kg})$ and $\mathrm{Pb}$ $(225 \mathrm{mg} / \mathrm{kg}), 30 \mathrm{~min}$ later. These regimens were administered orally by gavage once daily for a period of 9 weeks. At the end of the dosing period, the rats were sacrificed by jugular venisection after light chloroform anesthesia. Serum obtained from each blood sample was used to evaluate for the concentrations of triodothyronine (T3), thyroxine (T4), and thyroid stimulating hormone (TSH), while the thyroid gland was weighed and then evaluated for the malonaldehyde (MDA) concentration as an index of lipoperoxidation.
2.4. Evaluation of Concentrations of Triodothyronine-Thyroid Stimulating Hormone and Thyroxine. The concentrations of $\mathrm{T}_{3}, \mathrm{~T}_{4}$, and TSH were assayed using enzyme-linked immunosorbent assay (ELISA) kits (Microwell TSH, $\mathrm{T}_{3}, \mathrm{~T}_{4}$ kits; Synthron Bioresearch, Inc, USA).

\subsection{Effect of Treatments on Thyroid Gland Lipoperoxidation.} The level of thiobarbituric acid reactive substance, malonaldehyde (MDA) as an index of lipid peroxidation was evaluated in the thyroid gland using the double heating method of Draper and Hadley [41]. The principle of the method was based on spectrophotometric measurement of the color developed during reaction of thiobarbituric acid (TBA) with malonaldehyde. The thyroid glands from each animal in all the groups were weighed and then homogenized in a known volume of ice-cold phosphate buffer to obtain a $10 \%$ homogenate, which was centrifuged at $2000 \mathrm{~g}$ for $10 \mathrm{~min}$ to obtain the supernatant. The supernatant was then used to assess the level of protein and MDA in the sample. The assessment of MDA concentration in the supernatant of thyroid gland homogenate was performed thus; $2.5 \mathrm{~mL}$ of $100 \mathrm{~g} / \mathrm{L}$ trichloroacetic acid solution was added to $0.5 \mathrm{~mL}$ of the thyroid gland homogenate in a centrifuge tube and placed in a boiling water bath for $15 \mathrm{~min}$. After cooling under tap water for $5 \mathrm{~min}$, the mixtures were then centrifuged at $1000 \mathrm{~g}$ for $10 \mathrm{~min}$. $2 \mathrm{~mL}$ of the supernatant was added to $1 \mathrm{~mL}$ of $6.7 \mathrm{~g} / \mathrm{L}(0.67 \%)$ thiobarbituric acid (TBA) solution in a test tube and placed in a boiling water $\left(100^{\circ} \mathrm{C}\right)$ bath for $15 \mathrm{~min}$. The solution was cooled under tap water and the absorbance was thereafter measured at $532 \mathrm{~nm}$ using a UV spectrophotometer (T80 UV/VIS Spectrometer PG Instruments Ltd, UK). The concentration of MDA calculated by the absorbance coefficient of MDA-TBA complex $(1.56 \times$ $10^{5} \mathrm{~cm}^{-1}$ ) and expressed as $\mathrm{nmol} / \mathrm{mg}$ of tissue protein. The protein concentration was determined using the method described by Lowry et al. [42].

2.6. Statistical Analysis. Data obtained were expressed as mean + SEM and then subjected to one-way analysis of variance followed by Tukey's post hoc test using Graphpad prism version 4.0. Values of $P<.05$ were considered significant.

\section{Results}

3.1. Effect of Treatments on Serum Triiodothyronine Concentration. The effect of treatments on serum $\mathrm{T}_{3}$ level is shown in Figure 1. There was no significant difference in the serum $\mathrm{T}_{3}$ level between the groups. However, the $\mathrm{CPF}+\mathrm{Pb}$ group had the lowest $\mathrm{T}_{3}$ concentration with its level decreasing by $14.3 \%, 29 \%$, and $14.3 \%$, respectively, relative to the S/oil, VC, and $\mathrm{VC}+\mathrm{CPF}+\mathrm{Pb}$ groups.

\subsection{Effect of Treatments on Serum Thyroxine Concentration.} There was no significant $(P>.05)$ difference in the serum $\mathrm{T}_{4}$ level between the groups. However, the lowest $\mathrm{T}_{4}$ level was recorded in the $\mathrm{CPF}+\mathrm{Pb}$ group as its level decreased by $0.6 \%, 32 \%$, and $26 \%$ compared to S/oil, VC, and VC + $\mathrm{CPF}+\mathrm{Pb}$ groups, respectively (Figure 2 ). 


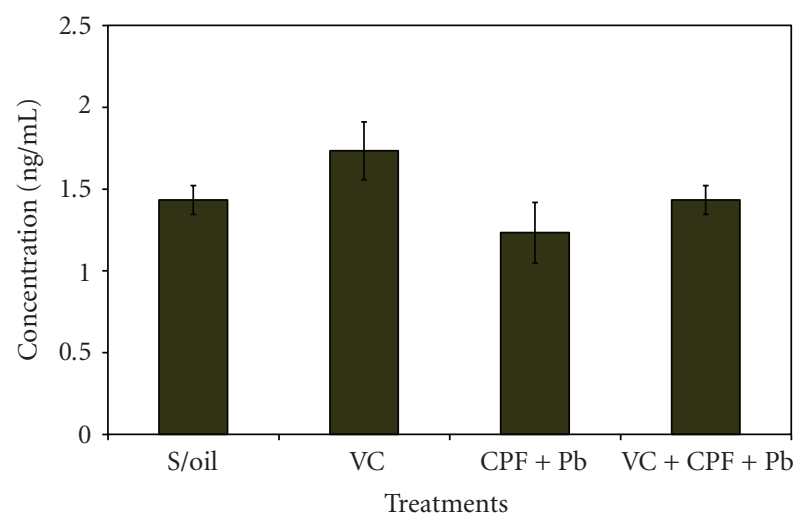

FIGURE 1: Effect of subchronic coexposure of soya oil (S/oil) and vitamin $\mathrm{C}$ (VC) and/or combination of chlorpyrifos (CPF) and lead $(\mathrm{Pb})$ on triodothyronine concentration in Wistar rats.

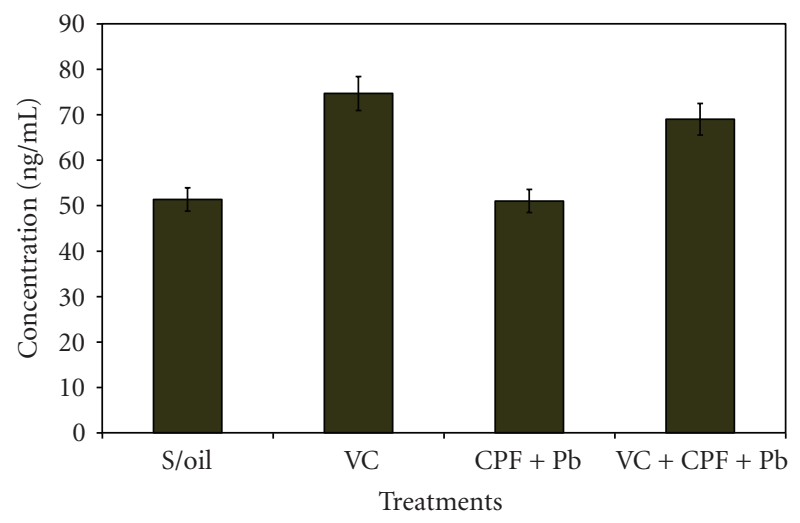

FIgURE 2: Effect of subchronic coexposure of soya oil (S/oil) and vitamin $\mathrm{C}$ (VC) and/or combination of chlorpyrifos (CPF) and lead $(\mathrm{Pb})$ on serum thyroxine concentration in Wistar rats.

3.3. Effect of Treatments on Serum Thyroid Stimulating Hormone Concentration. The effect of treatments on TSH concentration is shown in Figure 3. There was a significant $(P<.01)$ increase in the TSH concentration in $\mathrm{CPF}+\mathrm{Pb}$ group compared to S/oil group. The TSH concentration in the $\mathrm{VC}+\mathrm{CPF}+\mathrm{Pb}$ group significantly $(P<.05)$ increased compared to S/oil group. There was no significant $(P>.05)$ change in the TSH concentration in the VC group compared to $\mathrm{S} /$ oil, $\mathrm{CPF}+\mathrm{Pb}$, or $\mathrm{VC}+\mathrm{CPF}+\mathrm{Pb}$ group.

3.4. Effect of Treatments on Thyroid Malondialdehyde Concentration. The effect of treatments on thyroidal MDA concentration of various groups is shown in Figure 4. There was a significant $(P<.01)$ increase in the MDA concentration in the $\mathrm{CPF}+\mathrm{Pb}$ group when compared to $\mathrm{S} /$ oil, VC, or VC + CPF group. The MDA concentration significantly $(P<.01)$ increased in the $\mathrm{VC}+\mathrm{CPF}+\mathrm{Pb}$ group compared to VC group.

3.5. Effect of Treatments on the Weight of Thyroid Gland. The effect of treatments on the weight of thyroid gland is shown in Figure 5. There was no significant change $(P>.05)$ in the

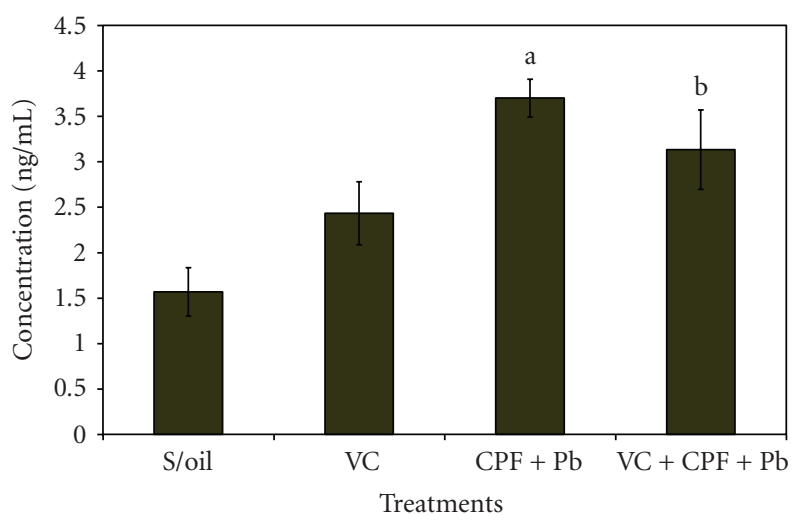

FIGURE 3: Effect of subchronic coexposure of soya oil (S/oil) and vitamin $\mathrm{C}(\mathrm{VC})$ and/or combination of chlorpyrifos (CPF) and lead $(\mathrm{Pb})$ on thyroid stimulating hormone concentration in Wistar rats. ${ }^{\mathrm{a}} \mathrm{P}<.01$ versus $\mathrm{S} /$ oil group, ${ }^{\mathrm{b}} \mathrm{P}<.05$ versus $\mathrm{S} /$ oil group.

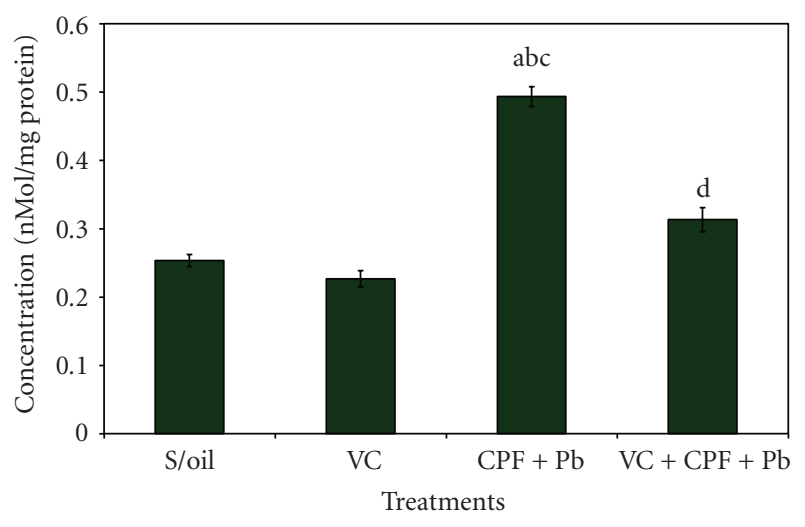

Figure 4: Effect of subchronic coexposure of soya oil (S/oil) and vitamin $\mathrm{C}(\mathrm{VC})$ and/or combination of chlorpyrifos (CPF) and lead $(\mathrm{Pb})$ on thyroid malonaldehyde concentration in Wistar rats. ${ }^{\text {abc }} \mathrm{P}<$ .01 versus S/oil, VC and VC $+\mathrm{CPF}+\mathrm{Pb}$ groups, respectively; ${ }^{\mathrm{d}} \mathrm{P}<$ .01 versus VC.

weight of the thyroid gland in between the groups. However, the thyroid weight was higher in the CPF group by $11.4 \%$, $8 \%$, and $7.2 \%$ relative to $\mathrm{C} / \mathrm{oil}, \mathrm{VC}$, and $\mathrm{VC}+\mathrm{CPF}$ groups, respectively.

\section{Discussion}

Low-dose subchronic coadministration of $\mathrm{CPF}$ and $\mathrm{Pb}$ mimicking environmental exposure, which did not cause any apparent systemic toxicity, has been shown to cause a nonsignificant decrease in the serum level of $\mathrm{T}_{3}$ and $\mathrm{T}_{4}$ in the present study. Although, the alteration in the concentration of thyroid hormone was not significant, the fact that these very low doses of $\mathrm{CPF}$ and $\mathrm{Pb}$ did cause some level of hormonal changes should not be ignored as it may indicate ongoing subclinical metabolic alterations within the system. CPF has been shown to induce hypothyroidism in ewes [22] and rats [23, 24, 43]. Zaidi et al. [44] recorded hypothyroidism in the serum of some pesticide formulators. Similarly, Meeker et al. [17] demonstrated an 


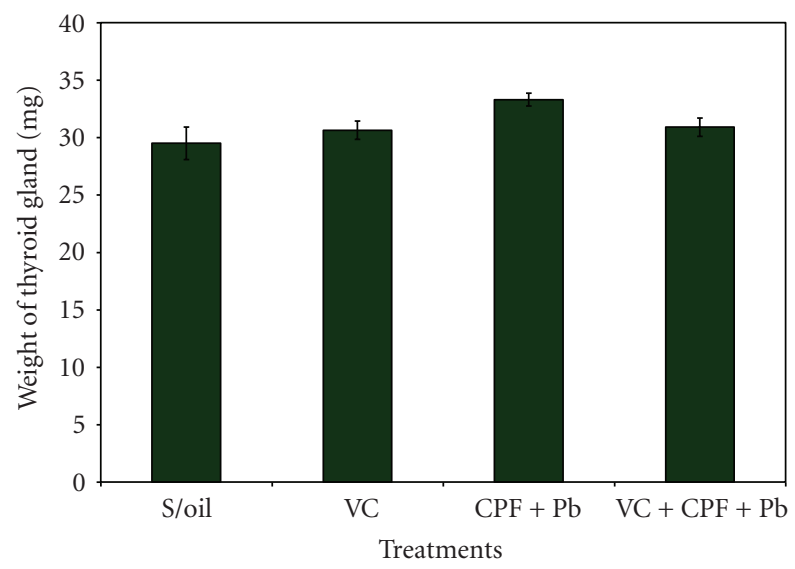

Figure 5: Effect of subchronic coexposure of soya oil (S/oil) and vitamin C (VC), and/or combination of chlorpyrifos (CPF) and lead $(\mathrm{Pb})$ on the weight of thyroid gland in Wistar rats.

inverse association between urinary concentration of CPF metabolites, 3,5,6-trichloro-2-pyridinol and $\mathrm{T}_{4}$ level and a positive association with TSH. In the same vein, hypothyroidism has been associated with $\mathrm{Pb}[45,46]$ poisoning. Perhaps the reason why the coadministration of $\mathrm{CPF}$ and $\mathrm{Pb}$ did not result in significant alteration in thyroid hormone concentrations may be due to the very low doses of the two chemicals used.

Although $\mathrm{T}_{3}$ is a poor indicator of subclinical or overt hypothyroidism, the marginal decrease in serum $\mathrm{T}_{3}$ level observed in the group subchronically coadministered with $\mathrm{CPF}$ and $\mathrm{Pb}$ may be due to the low $\mathrm{T}_{4}$ level observed in the group rather than a decrease synthesis. This is because $\mathrm{T}_{4}$ have to be converted to $\mathrm{T}_{3}$ for the biological effect of the hormone to be manifested. In addition, the relative low $\mathrm{T}_{3}$ level may also be due to deficiency in the synthesis of $5^{\prime}$-deiodionase, an enzyme responsible for the conversion of $\mathrm{T}_{4}$ to the more metabolically active $\mathrm{T}_{3}$. Indeed, $\mathrm{Pb}$ has been shown to inhibit the activity of type-I iodothyronine $5^{\prime}$-monodeiodinase $\left(5^{\prime}\right.$-D) activity [45]. CPF has been suggested to differentially affect peripheral deiodination [23]. The low $5^{\prime}$-deioodinase activity may have been due to pathological changes in the organs responsible for its synthesis by both $\mathrm{CPF}$ and $\mathrm{Pb}$.

The marginal decrease in the level of $\mathrm{T}_{4}$ observed in the group coadministered with $\mathrm{CPF}$ and $\mathrm{Pb}$ may be due to some level of damage to the thyroid acinar probably due to oxidative stress induction by both CPF $[23,24,43,44]$ and $\mathrm{Pb}[47,48]$. Although, the present study did not evaluate histological changes in the thyroid glands, $\mathrm{Pb}$ on its own has been shown to cause hypothyroidism either by inhibiting iodine uptake $[25,26]$ and to cause functional impairment of the pituitary-thyroid axis [27].

Some level of improvement in the concentration of $\mathrm{T}_{3}$ and $\mathrm{T}_{4}$ in group pretreated with vitamin $\mathrm{C}$ probably underscores the role of oxidative stress in thyroid dysfunction evoked by coadministration of $\mathrm{CPF}$ and $\mathrm{Pb}$ as indicated by low lipoperoxidative changes in the $\mathrm{VC}+\mathrm{CPF}+\mathrm{Pb}$ group. The vitamin $\mathrm{C}$ having protected the thyroid acinar from oxidative damage may have aided in restoring thyroid hormones' synthetic function. Apart from its antioxidant properties, some other nonantioxidant activity of vitamin $\mathrm{C}$ may have complemented the restoration of thyroidal function. For example, vitamin $\mathrm{C}$ has been demonstrated to aid the synthesis of paraoxonase, an important esterase that aids in the detoxification of OPs [49].

The significant increase in the TSH concentration in the group coadministered with $\mathrm{CPF}$ and $\mathrm{Pb}$ may be due to the attempt by the body to stimulate the thyroid gland to increase the synthesis and elaboration of $\mathrm{T}_{4}$ in order to compensate for the apparent deficit in the system. CPFinduced increase in TSH concentration has been recorded in humans $[17,44]$ and laboratory animal models $[23,24]$. The low $\mathrm{T}_{4}$ concentration in the $\mathrm{CPF}+\mathrm{Pb}$ group may have stimulated the hypothalamic neurons to secrete thyrotrophin releasing hormone (TRH) leading to increased stimulation of TSH synthesis [50]. The apparent normalization of the TSH concentration in group pretreated with vitamin $\mathrm{C}$ correlates positively with the marginal improvement in $\mathrm{T}_{4}$ and $\mathrm{T}_{3}$ concentration in the group.

The study revealed a significant increase in the MDA concentration in the thyroid gland of $\mathrm{CPF}+\mathrm{Pb}$ group as compared to other groups. This increased MDA concentration is indicative of oxidative damage to the thyroid gland. This may be attributed to the high metabolic rate, high level of free radicals accumulation, and low level of endogenous antioxidant in the thyroid gland. Oxidative stress induction is one of the molecular mechanism of CPF [31-33] and $\mathrm{Pb}[28,34]$ poisoning. Oxidative stress, characterized by an elevation in the steady-state concentration of reactive oxygen species (ROS), has been implicated in a wide range of biological and pathological conditions [51]. Thyroid hormones are associated with the oxidative and antioxidative status of the organism [52]. Because of its role in oxidative metabolism, increase concentration of ROS is formed in the thyroid glands. However, the combination of CPF and $\mathrm{Pb}$ was shown to have exacerbated the ROS induction perhaps due to their direct interaction with the thyroid acinar. Lipid peroxidation inactivates cell constituents by oxidation or causes oxidative stress by undergoing radical chain reaction, ultimately leading to loss of membrane integrity [53]. Similarly, the increased MDA concentration may have been exacerbated due to impairment of antioxidant enzymes that have been reported in hypothyroidism [54]. Pb on its own induces lipoperoxidation by inhibiting the activity of $\delta$-aminolevulinic acid dehydrase leading to accumulation of its substrate $\delta$-aminolevulinic acid, which rapidly oxidize to generate free radicals as superoxide ion, hydroxyl radical, and hydrogen peroxide [7].

Pretreatment with vitamin $\mathrm{C}$ has been shown by the present study to ameliorate the lipoperoxidative changes induced by subchronic administration of coadministration of $\mathrm{CPF}$ and $\mathrm{Pb}$. This was apparently due to antioxidant property of the vitamin. The antioxidant properties of vitamin $\mathrm{C}$ have been demonstrated in numerous studies involving CPF-induced lipoperoxidation [31, 33, 37, 38].

The weight of the thyroid was marginally higher in the $\mathrm{CPF}+\mathrm{Pb}$ group than any of the other three groups. The 
reason for the relatively higher weight in the $\mathrm{CPF}+\mathrm{Pb}$ group may be related to the significantly higher TSH concentration, which may have partly stimulated the proliferation of the thyroid follicular cell [55], apparently to compensate for the marginal decrease in thyroid hormones. Although, the weight of the thyroid gland was marginally higher in the group pretreated with vitamin $\mathrm{C}$ than those of C/oil and $\mathrm{VC}$ groups, the fact that it was lower compared to $\mathrm{CPF}+\mathrm{Pb}$ group demonstrates apparent restoration of the weight of the thyroid gland by vitamin C.

\section{Conclusion}

Subchronic coadministration of $\mathrm{CPF}$ and $\mathrm{Pb}$ has been shown by the present study to marginally decrease thyroid hormones concentration, increase TSH concentration and thyroid lipoperoxidation, and marginally increase the weight of the thyroid gland. The alterations in these thyroid gland parameters were ameliorated by pretreatment with vitamin $\mathrm{C}$ apparently due to its antioxidant properties.

\section{References}

[1] A. Brouwer, D. C. Morse, M. C. Lans et al., "Interactions of persistent environmental organohalogens with the thyroid hormone system: mechanisms and possible consequences for animal and human health," Toxicology and Industrial Health, vol. 14, no. 1-2, pp. 59-84, 1998.

[2] M. G. Wade, G. K. Warren, V. Y. Edwards et al., "Effects of subchronic exposure to a complex mixture of persistent contaminants in male rats: systemic, immune and reproductive effects," Toxicological Sciences, vol. 67, pp. 131-143, 2002.

[3] J. E. Casida and G. B. Quistad, "Organophosphate toxicity: safety aspects of non acetylcholinesterase secondary targets," Chemical Research in Toxicology, vol. 17, no. 8, pp. 983-998, 2004.

[4] S. M. Levin and M. Goldberg, "Clinical evaluation and management of lead-exposed construction workers," American Journal of Industrial Medicine, vol. 37, no. 1, pp. 23-43, 2000.

[5] Y. Lolin and P. O'Gorman, " $\delta$-Aminolaevulinic acid dehydratase as an index of the presence and severity of lead poisoning in acute and chronic lead exposure," Annals of Clinical Biochemistry, vol. 23, no. 5, pp. 521-528, 1986.

[6] L. M. Fels, M. Wünsch, J. Baranowski et al., "Adverse effects of chronic low level lead exposure on kidney function-a risk group study in children," Nephrology Dialysis Transplantation, vol. 13, no. 9, pp. 2248-2256, 1998.

[7] H. Gurer-Orhan, H. U. Sabir, and H. Ozgüneş, "Correlation between clinical indicators of lead poisoning and oxidative stress parameters in controls and lead-exposed workers," Toxicology, vol. 195, no. 2-3, pp. 147-154, 2004.

[8] H. Krishna and A. V. Ramachandran, "Biochemical alterations induced by the acute exposure to combination of chlorpyrifos and lead in Wistar rats," Biology and Medicine, vol. 1, no. 2, pp. $1-6,2009$.

[9] N. S. Duzgoren-Aydin, "Sources and characteristics of lead pollution in the urban environment of Guangzhou," Science of the Total Environment, vol. 385, no. 1-3, pp. 182-195, 2007.

[10] A. M. Saleh, C. Vijayasarathy, L. Masoud, L. Kumar, A. Shahin, and A. Kambal, "Paraoxon induces apoptosis in EL4 cells via activation of mitochondrial pathways," Toxicology and Applied Pharmacology, vol. 190, no. 1, pp. 47-57, 2003.

[11] R. Sandhir, D. Julka, and K. D. Gill, "Lipoperoxidative damage on lead exposure in rat brain and its implications on membrane bound enzymes," Pharmacology and Toxicology, vol. 74, no. 2, pp. 66-71, 1994.

[12] L. Patrick, "Lead toxicity part II: the role of free radical damage and the use of antioxidants in the pathology and treatment of lead toxicity," Alternative Medicine Review, vol. 11, no. 2, pp. 114-127, 2006.

[13] W. Zheng, M. Aschner, and J. F. Ghersi-Egea, "Brain barrier systems: a new frontier in metal neurotoxicological research," Toxicology and Applied Pharmacology, vol. 192, no. 1, pp. 1-11, 2003.

[14] P. C. Hsu, M. Y. Liu, C. C. Hsu, L. Y. Chen, and Y. Leon Guo, "Lead exposure causes generation of reactive oxygen species and functional impairment in rat sperm," Toxicology, vol. 122, no. 1-2, pp. 133-143, 1997.

[15] P. C. Hsu, C. C. Hsu, M. Y. Liu, L. Y. Chen, and Y. L. Guo, "Lead-induced changes in spermatozoa function and metabolism," Journal of Toxicology and Environmental Health Part A, vol. 55, no. 1, pp. 45-64, 1998.

[16] J. D. Meeker, L. Ryan, D. B. Barr et al., "The relationship of urinary metabolites of carbaryl/naphthalene and chlorpyrifos with human semen quality," Environmental Health Perspectives, vol. 112, no. 17, pp. 1665-1670, 2004.

[17] J. D. Meeker, L. Ryan, D. B. Barr, and R. Hauser, "Exposure to nonpersistent insecticides and male reproductive hormones," Epidemiology, vol. 17, no. 1, pp. 61-68, 2006.

[18] M. Iwasaki, I. Sato, Y. Jin, N. Saito, and S. Tsuda, "Problems of positive list system revealed by survey of pesticide residue in food," Journal of Toxicological Sciences, vol. 32, no. 2, pp. 179184, 2007.

[19] S. C. Joshi, R. Mathur, and N. Gulati, "Testicular toxicity of chlorpyrifos (an organophosphate pesticide) in albino rat," Toxicology and Industrial Health, vol. 23, no. 7, pp. 439-444, 2007.

[20] S. F. Ambali, S. O. Abbas, M. Shittu et al., "Effects of gestational exposure to chlorpyrifos on implantation and neonatal mice," Journal of Cell and Animal Biology, vol. 3, no. 4, pp. 050-057, 2009.

[21] S. F. Ambali, H. O. Imana, M. Shittu, M. U. Kawu, S. O. Salami, and J. O. Ayo, "Effect of chlorpyrifos on pre-implantation loss in Swiss Albino mice," Journal of Agriculture and Biology of North America, vol. 1, no. 2, pp. 152-155, 2010.

[22] N. C. Rawlings, S. J. Cook, and D. Waldbillig, "Effects of the pesticides carbofuran, chlorpyrifos, dimethoate, lindane, triallate, trifluralin, 2,4-D, and pentachlorophenol on the metabolic endocrine and reproductive endocrine system in ewes," Journal of Toxicology and Environmental Health Part A, vol. 54, no. 1, pp. 21-36, 1998.

[23] S. De Angelis, R. Tassinari, F. Maranghi et al., "Developmental exposure to chlorpyrifos induces alterations in thyroid and thyroid hormone levels without other toxicity signs in CD-1 mice," Toxicological Sciences, vol. 108, no. 2, pp. 311-319, 2009.

[24] S. F. Ambali, Ameliorative Effect of Vitamins $C$ and $E$ on Neurotoxicological, Hematological and Biochemical Changes Induced by Chronic Chlorpyrifos in Wistar Rats, Ph.D. thesis, Ahmadu Bello University, Zaria, Nigeria, 2009.

[25] D. W. Slingerland, "The infleunce of various factors on the uptake of iodine by the thyroid," Journal of Clinical Endocrinology and Metabolism, vol. 15, pp. 131-141, 1955. 
[26] H. H. Sandstead, E. G. Stant, A. B. Brill, L. I. Arias, and R. T. Terry, "Lead intoxication and the thyroid," Archives of Internal Medicine, vol. 123, no. 6, pp. 632-635, 1969.

[27] B. Singh, V. Chandran, H. K. Bandhu et al., "Impact of lead exposure on pituitary-thyroid axis in humans," Biometals, vol. 13, no. 2, pp. 187-192, 2000.

[28] O. O. Oladipo, Ameliorative Effects of Ascorbic Acid on Neurobehavioural, Haematological and Biochemical Changes Induced by Subchronic Lead Exposure in Wistar Rats, M.S. thesis, Ahmadu Bello University, Zaria, Nigeria, 2010.

[29] B. D. Banerje, V. Seth, A. Bhattacharya, S. T. Pasha, and A. K. Chakraborty, "Biochemical effects of some pesticides on lipid peroxidation and free radical scavengers," Toxicology Letters, vol. 107, pp. 33-47, 1999.

[30] F. Gultekin, N. Delibas, S. Yasar, and I. Kilinc, "In vivo changes in antioxidant systems and protective role of melatonin and a combination of vitamin $\mathrm{C}$ and vitamin $\mathrm{E}$ on oxidative damage in erythrocytes induced by chlorpyrifos-ethyl in rats," Archives of Toxicology, vol. 75, no. 2, pp. 88-96, 2001.

[31] S. F. Ambali, S. B. Idris, C. Onukak, M. Shittu, and J. O. Ayo, "Ameliorative effects of vitamin C on short-term sensorimotor and cognitive changes induced by acute chlorpyrifos exposure in Wistar rats," Toxicology and Industrial Health, vol. 26, no. 9, pp. 547-558, 2010.

[32] S. F. Ambali, J. O. Ayo, S. A. Ojo, and K. A. N. Esievo, "Vitamin E protects rats from chlorpyrifos-induced increased erythrocyte osmotic fragility in Wistar rats," Food and Chemical Toxicology, vol. 48, pp. 3477-3480, 2010.

[33] S. F. Ambali, J. O. Ayo, S. A. Ojo, and K. A. N. Esievo, "Ameliorative effect of vitamin $\mathrm{C}$ on chlorpyrifos-induced increased erythrocyte fragility in Wistar rats," Human and Experimental Toxicology, vol. 30, no. 1, pp. 19-24, 2011.

[34] E. G. Moreira, I. Vassilieff, and V. S. Vassilieff, "Developmental lead exposure: behavioral alterations in the short and long term," Neurotoxicology and Teratology, vol. 23, no. 5, pp. 489495, 2001.

[35] M. K. Nihei, J. L. McGlothan, C. D. Toscano, and T. R. Guilarte, "Low level $\mathrm{Pb}^{2+}$ exposure affects hippocampal protein kinase $\mathrm{Ca} f$ gene and protein expression in rats," Neuroscience Letters, vol. 298, no. 3, pp. 212-216, 2001.

[36] K. Slawomir, K. Aleksandra, S. Horakb et al., "Activity of SOD and catalase in people protractedly exposed to lead compounds," Annals of Agricultural and Environmental Medicine, vol. 11, pp. 291-296, 2004.

[37] S. Ambali, D. Akanbi, N. Igbokwe, M. Shittu, M. Kawu, and J. Ayo, "Evaluation of subchronic chlorpyrifos poisoning on hematological and serum biochemical changes in mice and protective effect of vitamin C," Journal of Toxicological Sciences, vol. 32, no. 2, pp. 111-120, 2007.

[38] G. G. El-Hossary, S. M. Mansour, and A. S. Mohamed, "Neurotoxic effects of chlorpyrifos and the possible protective role of antioxidant supplements: an experimental study," Journal of Applied Sciences Research, vol. 5, no. 9, pp. 1218 1222, 2009.

[39] R. C. Patra, D. Swarup, and S. K. Dwivedi, "Antioxidant effects of $\alpha$ tocopherol, ascorbic acid and L-methionine on lead induced oxidative stress to the liver, kidney and brain in rats," Toxicology, vol. 162, no. 2, pp. 81-88, 2001.

[40] "Guide for the care and use of laboratory animals," DHEW Publication No. (NIH) 85-23, Office of Science and Health Reports, DRR/NIH, Bethesda, Md, USA, 1985.

[41] H. H. Draper and M. Hadley, "Malondialdehyde determination as index of lipid peroxidation," Methods in Enzymology, vol. 186, pp. 421-431, 1990.
[42] O. H. Lowry, N. J. Rosebrough, A. L. Farr, and R. J. Randall, "Protein measurement with the Folin phenol reagent," The Journal of Biological Chemistry, vol. 193, no. 1, pp. 265-275, 1951.

[43] S. H. Jeong, B. Y. Kim, H. G. Kang, H. O. Ku, and J. H. Cho, "Effect of chlorpyrifos-methyl on steroid and thyroid hormones in rat F0- and F1-generations," Toxicology, vol. 220, no. 2-3, pp. 189-202, 2006.

[44] S. S. A. Zaidi, V. K. Bhatnagar, S. J. Gandhi, M. P. Shah, P. K. Kulkarni, and H. N. Saiyed, "Assessment of thyroid function in pesticide formulators," Human and Experimental Toxicology, vol. 19, no. 9, pp. 497-501, 2000.

[45] S. S. Chaurasia, S. Panda, and A. Kar, "Lead inhibit type1 iodothyronine $5^{1}$-monodeinodinase in the Indian rock pigeon Columba livia: a possible involvement of essential thiol groups," Journal of Biosciences, vol. 22, no. 2, pp. 247-254, 1997.

[46] K. Badiei, P. Nikghadam, K. Mostaghni, and M. Zariti, "Effect of lead on thyroid function in sheep," Iranian Journal of Veterinary Research Shiraz University, vol. 10, no. 3, Ser. no. 28, pp. 223-227, 2009.

[47] M. K. Kale, S. N. Umathe, and K. P. Bhusari, "Oxidative Stress and the Thyroid," Positive Health, http://www.encognitive .com/files/Oxidative $\% 20$ Stress $\% 20$ and $\% 20$ the $\% 20$ Thyroid_0 .pdf, 2006.

[48] M. Ahamed and M. K. J. Siddiqui, "Low level lead exposure and oxidative stress: current opinions," Clinica Chimica Acta, vol. 383, no. 1-2, pp. 57-64, 2007.

[49] G. P. Jarvik, N. T. Tsai, L. A. McKinstry et al., "Vitamin C and E intake is associated with increased paraoxonase activity," Arteriosclerosis, Thrombosis, and Vascular Biology, vol. 22, no. 8, pp. 1329-1333, 2002.

[50] S. Nussey and S. A. Whitehead, Endocrinology: An Integrated Approach, Bios Scientific Publishers, Oxford, UK, 2001.

[51] Z. E. Suntres and E. M. K. Lui, "Antioxidant effect of zinc and zinc-metallothionein in the acute cytotoxicity of hydrogen peroxide in Ehrlich ascites tumour cells," Chemico-Biological Interactions, vol. 162, no. 1, pp. 11-23, 2006.

[52] A. A. Alturfan, E. Zengin, N. Dariyerli et al., "Investigation of zinc and copper levels in methimazole-induced hypothyroidism: relation with the oxidant-antioxidant status," Folia Biologica, vol. 53, no. 5, pp. 183-188, 2007.

[53] M. A. Abdel-Wahhab and S. E. Aly, "Antioxidant property of Nigella sativa (black cumin) and Syzygium aromaticum (clove) in rats during aflatoxicosis," Journal of Applied Toxicology, vol. 25, no. 3, pp. 218-223, 2005.

[54] D. K. Sahoo, A. Roy, S. Bhanja, and G. B. N. Chainy, "Hypothyroidism impairs antioxidant defence system and testicular physiology during development and maturation," General and Comparative Endocrinology, vol. 156, no. 1, pp. 63-70, 2008.

[55] A. Hood, Y. P. Liu, V. H. Gattone, and C. D. Klaassen, "Sensitivity of thyroid gland growth to thyroid stimulating hormone (TSH) in rats treated with antithyroid drugs," Toxicological Sciences, vol. 49, no. 2, pp. 263-271, 1999. 


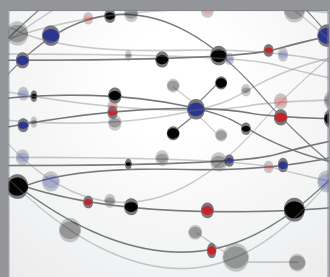

The Scientific World Journal
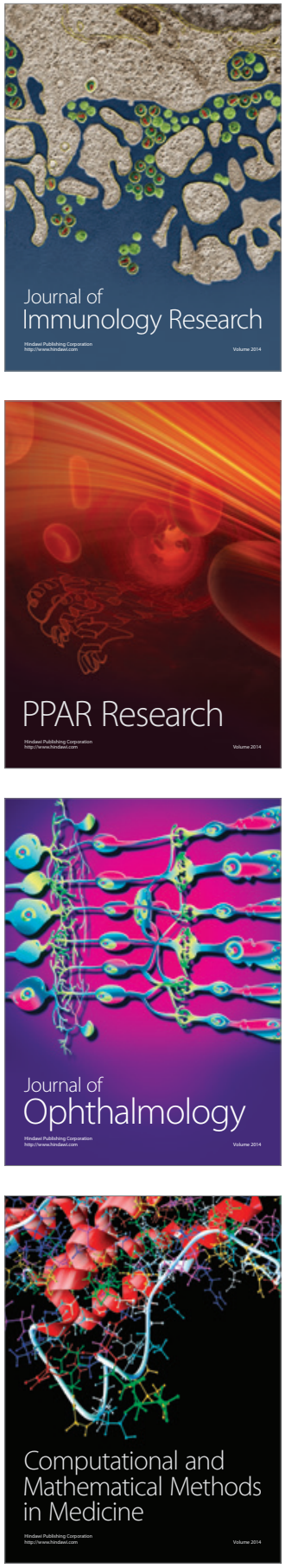

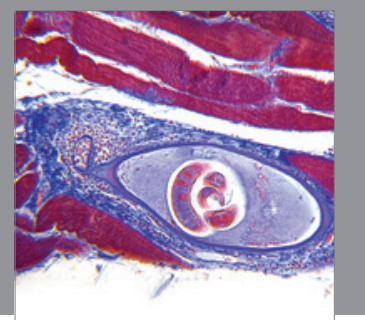

Gastroenterology

Research and Practice
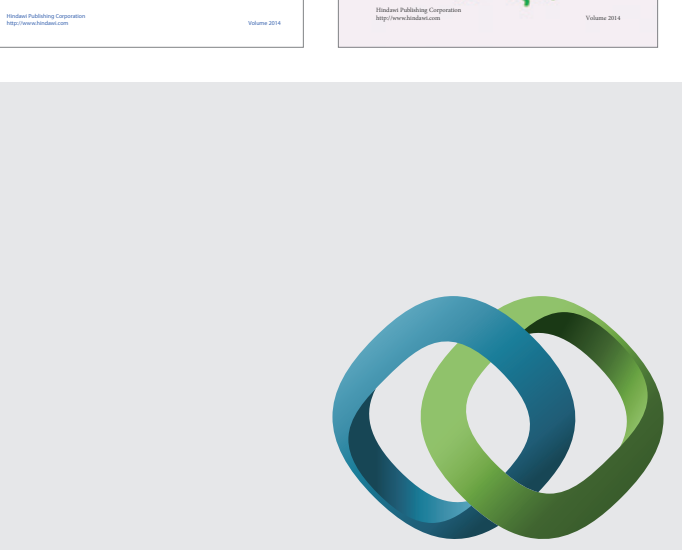

\section{Hindawi}

Submit your manuscripts at

http://www.hindawi.com
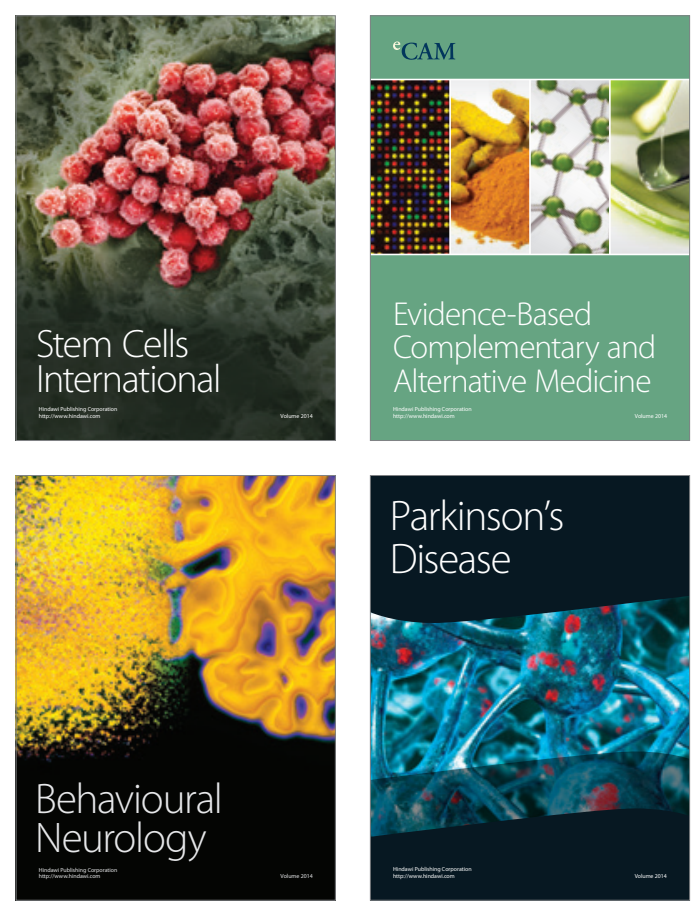

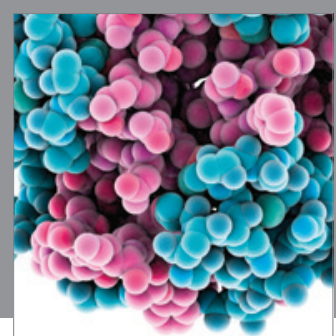

Journal of
Diabetes Research

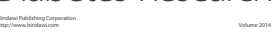

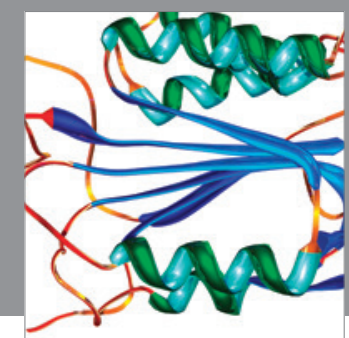

Disease Markers
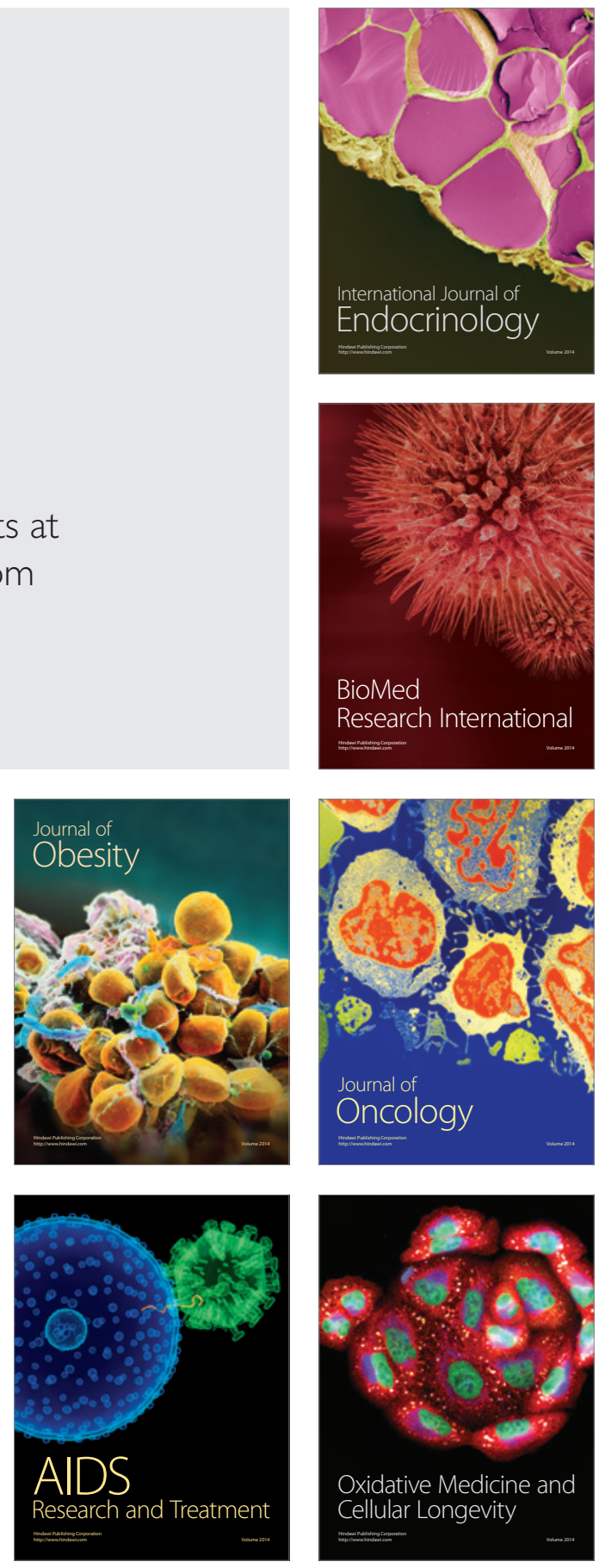